\title{
Unsynchronized evolution of salinity and pH of a Permian alkaline lake influenced by hydrothermal fluids
}

\author{
LIUWEN XIA ${ }^{1 *}$, JIAN CAO ${ }^{1}$, EVA E. STÜEKEN ${ }^{2,3}$, \\ DONGMING Z ZH ${ }^{4}$, TINGTING WANG, WENWEN Li
}

1 School of Earth Sciences and Engineering, Nanjing

University, Nanjing, Jiangsu 210023, China

${ }^{2}$ School of Earth \& Environmental Sciences, University of St Andrews, St Andrews KY16 9AL, Scotland, UK

${ }^{3}$ NASA Astrobiology Institute, Virtual Planetary Laboratory, University of Washington, Seattle, WA 98195, USA

${ }^{4}$ PetroChina Xinjiang Oilfield Company, Karamay, Xinjiang 843000 , China

In saline and alkaline lakes, hyperalkaline waters display unusually high productivity, which makes them prime targets in the search for life in the solar system. However, their formation mechanisms are not well understood, because the response of biogeochemical proxies to these conditions is poorly constrained. To improve the understanding of this issue, in this work, the influence of hydrothermal fluids on the salinity and $\mathrm{pH}$ of alkaline lakes is discussed, based on a case study of an early Permian paleo-alkaline lake ( $\sim 290 \mathrm{Ma}$; Fengcheng Formation) in the Mahu Sag, northwestern Junggar Basin, China.

Multiple geochemical proxies indicate that hydrothermal fluids in the central salt rock and marginal tuff-mudstone areas of the Fengcheng Formation were affected by deep and shallow hydrothermal fluids, respectively. A small part of the transitional area was affected by hydrothermal fluids with a hybrid nature. The hydrothermal fluid activity gradually weakened up-section in all areas while salinity (inferred from carbon and oxygen isotopes) increased and $\mathrm{pH}$ (inferred from nitrogen isotopes and mineralogy) decreased from hyperalkaline $(>9.25)$ to moderately alkaline conditions. These trends suggest that hyperalkalinity was largely driven by hydrothermal processes. In contrast, evaporation, which dominated towards the end of the lake's lifetime, maintained an elevated $\mathrm{pH}$ but did evidently not have a similarly strong effect as hydrothermal fluids.

Our data suggest that hydrothermal activity and evaporation in closed lacustrine basins has the potential to create extreme conditions for the formation of alkaline lakes, and the evolution of salinity and $\mathrm{pH}$ are unsynchronized. 